DOI: $10.2478 /$ ausfm-2020-0005

\title{
Modern Classic in the Web Environment: Narrative Variations of V. Nabokov's Lolita in Fanfiction
}

\author{
Anastasiia Drozdova and Vladimir Petrov \\ University of Tyumen (Russia) \\ E-mails: an.o.droz@gmail.com, petrov.v.1337@gmail.com
}

\begin{abstract}
The main focus of this paper is on the narrative strategy used by fan writers in the process of interpretation of a modern classic. The research is based on the hypothesis that text-interpretation implements the existing yet implicit narrative lines of an original source. The discussion focuses on Vladimir Nabokov's œuvre represented by the novel Lolita in amateur writers' communities. The article's hypothesis is that due to the existence of English and Russian versions of Lolita, fan texts in both corpora differ in the choice of linguistic means, but use similar narrative structures (Greimas). Whenever the narrative scheme is not oversimplified to resemble the model of a mass literature novel, it follows Humbert's confession scheme in a way the character himself wants the fictional reader to perceive it. If the name of one of the actants is omitted or the two-actant model is expanded, the amateur text is close to the plot of the novel and its auto-citation structure. The novel, devoted to the story about an erroneous interpretation, is open to any mass-media adaptations. The original narrative strategy of Lolita is more exposed through the fan adaptations: the active reader is an obligatory participant in the artistic creation. ${ }^{1}$
\end{abstract}

Keywords: fanfiction, transmedial translation, Vladimir Nabokov, Lolita, actantial models.

\section{Introduction}

Modern classics and their screen adaptations are always transformed in the interactive digital sphere, where the communities of readers or viewers discuss the arts and create their own works, based on the original film or novel. These amateur

1 The study was funded by the Russian Foundation for Basic Research, within the research project № 18-312-00127. 
works reflect the individual interpretation of texts. In this case, the internet is a medium where consumers and authors "collide" (Jenkins 2006, 2): the reception of texts is an independent object for criticism and assessment. International online sources and archives such as Archive of Our Own, Fan Fiction, and Kniga Fanfikov are the space where readers' and viewers' creativity can manifest itself in different forms: reviewing other fan texts, shaping the fictional world based on the original source, writing stories (Magnifico et al. 2015, 158-159).

Despite a lot of fanfiction being based on films or TV series (Fiske 2001, 46), the most popular form of audience creativity includes verbal texts in which visual methods and techniques are transposed to the fictional narration. The appeal to the original plot or scenario in fanfiction is connected with "ritualized viewing" (Brooker 2017, 164) and high degree of fans' identification with fictional characters (McGee 2005, 165): verbal texts are the results of emotional engagement, when the literary or film criticism on the one hand and personal experience on the other are combined (Barnes 2015, 75).

Hitherto, fan practice has been researched as a form of adaptation, interpretation and re-reading inherent in fan community. If fans freely change the original text, does it itself respond to their changes? What is the relationship between an original and a fan narration? The understanding of a fan text from these positions originates from Roland Barthes's conception of text-as-reading and his conception of author and authority: "the most subjective reading imaginable is never anything but a game played according to certain rules" (Barthes 1989, 31).

The basis of our research is the statement that text-interpretation implements the existing, yet implicit narrative lines of the original source. Thus, potential strategies of the text itself live in its reader adaptations presented in the interactive media. Lolita is one of the fandoms where fan texts are equally influenced by both the movie adaptations and the original novel. The multiplicity of intermediary translations determines the international existence of V. Nabokov's Lolita as a part of Englishand Russian-speaking cultures. Identifying fan narrative strategies determined by the language and culture of reading and observation is one of the objectives of our study. The research of fan stories based on Lolita notes that the existence in an interlingual and intermedial environment itself is due to the interpretation strategies embodied in the original text. 


\section{Methodology}

We turned to fanfiction depositories as the source of the study material. When choosing web-sources for our research, we were guided by several factors:

1) The availability of data - the number of texts whose authors use various forms of media should be sufficient to represent a community of Lolita's fans. In global fic writers' community there are three non-commercial depositories that contain both original texts and texts that can be published on small resources and even on private web-pages, particularly FanFiction, Archive of Our Own, and Kniga Fanfikov (over $2,000,5,000$, and 4,000 literary fandoms respectively). These sites are the biggest archives of texts based on novels, films, music, and advertisements connected with Nabokov's Lolita.

The information about fandoms and the texts contained in them are open to any user. Not all fandoms have the same number of texts, and the difference between a popular and unpopular fandom is sometimes very sizeable. We found that there are about $10-17 \%$ of fandoms with over 50 texts and about $40-50 \%$ of fandoms with 1-3 texts. The popularity of the texts based on Lolita is sufficient on the English websites (17 texts on FanFiction and 23 texts on Archive of Our Own) and is comparatively higher on the Russian platform (89 texts on Kniga Fanfikov).

2) Users' involvement in active discussion of other people's work and in cocreation. In a fan community, each text is a part of a forum where an author can discuss his or her work with readers.

3) Interface features including categories selected by fan authors' community itself. The interface of the sites should allow fic writers to communicate freely with each other, make individual selections of texts and edit their own works in response to criticism. So, fanfiction as a phenomenon of the new media has the property of automation and variability (Manovich 2001, 27-30). Thus, any user can create an individual collection (or "blocks of data" [Manovich 2001, 97]) of texts based on their own requests and add or update their own texts without changing the structure of the entire database. Thus, the fanfiction depositories FanFiction, Kniga Fanfikov, and Archive of Our Own are representative for researching a fan's interpretation of Lolita.

The intermediality of fanfiction is explicit in the original genre system created by fic writers that allows them to create fanfiction based on films, literature, music, and video games. These genres are common in different media forms (for fanfiction genres see Viires [2005, 165]). The need to develop such classification system occurs 
because fanfiction not only involves different media, but also presumes interaction and interference of various cultural practices in itself.

During the first stage of our research, we compiled the study material - the works listed under the tag "Lolita, V. Nabokov." This tag reflects that amateur writers consider their work as a form of reader creativity. Generally, when fanfiction authors affiliate their text to the "canon" by tagging, they explicate their affiliation to the readers' community (they receive "textual identity” [Black 2006, 172]). We cannot use tags for more discrete text analysis because the users who post their texts on the resource set the system of tags and keywords themselves. Individual tags cannot verify the features of amateur text interpretation.

During the second stage of the research - studying the methods of textual interpretation in detail, we explore the linguistic features of texts that are used to transform different types of media. This is predominantly manifested on the rhythmic or lexical levels, which are associated with the genres chosen by the fic writers: we consider the metaphor, wordplay or keywords with common semantics that connect a secondary text to the original source. Here we follow the statement of G. Leech that "linguistic deviation is essential to a linguistic account of literary language" (2013, 14): fic writers copy the explicit features of the language of the source text and thereby make its peculiarities common for all participants of a fandom.

One of the possible forms of classifying and studying a fandom and corpora of fan texts surrounding it is the detection of stable components in the narration. Using these components, fan writers realize potential narrative lines, "text's potential future" (Johnson 2007, 286), implied in the plot of the original text.

The actantial model ("modéle actantiel," Greimas 1986, 174) offers a quantitative indicator for the analysis of fanfiction corpora and reflects the properties of the structure of individual texts. Some observations of the actantial structure in fanfiction were carried out by Mar Guerrero-Pico, who noticed the interrelations between actants, the structure of fanfiction, and its genre incarnation (GuerreroPico 2016, 80). The theory of actantial model is a universal tool for the analysis of narration in fiction and non-fiction. The theory is based on V. Propp's (2003) classification of characters in a folktale, which describes three axes that are in constant interaction and have specific functions: the axes of desire (subject and object), power (helper and opponent), and transmission (sender/receiver) (Greimas 1986, 218). The model is used as a description method in different research: gender analysis of the cinema (Fernández-Morales and Menéndez-Menéndez 2013), analysis of journalistic texts (Aarva and Tampere 2006) and literature (Woloch 2003). Moreover, the theory of actantial models allows us to classify fanfiction texts 
in accordance with the narrative strategies that have been chosen as a result of readers' individual reception.

The advantage of using such narrative grammar in the analysis of amateur transcriptions is that the actantial model takes into account the hybridity of fanfiction texts (and, in general, of digital media), which are based not only on literature, but also on movies, video games, and music; it also includes the transformation of different media. The main feature of the Lolita fandom is the use of the structures of the novel and Stanley Kubrick's (1962) or Adrian Lyne's (1997) movies as a single source. Moreover, it is difficult to define which elements of a fanfic were created exclusively on the model of the film adaptations and which on the model of Nabokov's novel. A lot of fan texts combine Lolita's narration and plots of mass literature, TV series, and cartoons (about 21\% of the whole corpora). The research of actantial models will allow us to understand why Lolita is used by amateur authors as a text open to intermedial creation.

\section{Related Works}

Fanfiction as a phenomenon of media, literature, and culture has been the centre of interdisciplinary research since the 1980-1990s. Initially, there was a stereotyping view of fan culture (Jenkins 1992, 12-13) that was considered as a part of "pluralistic culture” (DiMaggio 1977, 447). Early studies describe fans as a socially, politically, and economically determined community (Jewett and Laurence 1977; Burchill 1986).

The most influential direction in fan studies coincides with the appearance of new methods in social and anthropology studies. Henry Jenkins's approach, outlined in his book Textual Poachers, impacts the subsequent research and determines the primary goals of fanfiction studies in general. Jenkins $(1992,4)$ defines a new direction in culture research: there is "no privileged position from which to survey a culture." Fan interpretations do not always include the conventional meaning of the canon: "fan critics work to resolve gaps, to explore excess details and undeveloped potentials" (Jenkins 1992, 284). The variety of strategies of fan interpretation and methods they use to play with the original source allows us to classify fanfiction as one of the forms of "transmedial translation:" "transmedia storytelling represents a process where integral elements of a fiction get dispersed systematically across multiple delivery channels" (Jenkins 2007).

According to Bronwen Thomas, the first wave of fan studies established readers' dependent position on consumer practice and disproved it, then the second wave 
observed the inner mechanisms of power distribution in fan communities (Thomas 2015, 4). Describing the duality of a commercial movie and a cult movie, Mark Jancovich $(2002,307-308)$ notices the inner mechanism of influencing fandom and provoking active communication within it. In our research, this peculiarity of a cult movie fandom is very important: a fandom based on classical literature as a high culture considers the strategy of both mass and niche media.

As Thomas notices, the third wave of fan studies investigates the paratexts that surround fan community, underscoring the connections between fan practice and contemporary culture; the third wave is also distinguished by interest in forms of fan creation in "everyday life" (Thomas 2015, 4). The research methods of this wave are presented in the book Fandom: Identities and communities in a mediated world (Gray 2017). Researchers refuse to define fans as part of the high and low cultures, and show how fans take part in the creation of different media. This wave investigates a different form of fan practice and perceives fans as part of a subculture. For example, John Tulloch, the author of the first fan studies research devoted to readers of Russian classics, noticed a strong pattern in theatregoers' interpretation of Chekhov's work (Tulloch, 2007). His study convinces us that the conventional scholarly discussion of classical literature determines ways of fans' interpretations.

We also suggest that fan studies which are focused on the unfolding fictional world might amplify theoretical approaches using the tools of adaptational studies. Christopher Marlow (2009) studied various forms of textual adaptations in his work devoted to the fanfiction on Doctor Who TV series. There he suggests that adaptation research deals with complex narrative "traits and sequences," where the text "quotes, displaces or folds itself” (Marlow 2009, 48).

In order to show the "elasticity of the storyworlds" (Thomas 2015, 10), with which fic writers interact, a lot of researchers turn to the methods of narratology. Cornel Sandvoss (2007) mentions Roland Barthes's conception of an Author and his "condition of textuality" where "text's unity lies not in its origin but in its destination" (Barthes 1977, 148). Describing the narrative strategies of "gap filling," Sandvoss $(2007,29)$ uses Iser's notion of "normalization." Bronwen Thomas $(2015$, 10-13) lists the whole corpora of variations using the narrative terminology in fan studies. As we suggest, the centre of each work is occupied by one dominant narrative category: hyperdiegesis (Hills 2012), encyclopedic narrative (Murray, 2017), story mode (Bedows, 2012), narrative frame (Steenhuyse, 2014). These terms allow us to describe peculiarities of the narration such as the intersection of plot lines as an inherent characteristic of fan writing. 
In fanfiction, the boundary between different types of perception is erased: the author of a fanfic is simultaneously a spectator, a listener, and a reader; herewith, to create fanfiction means to mix different types of such experiences and their digitalization. The history of development, as well as the hybridity of the fan writing attribute fanfics and fan-sites to "new media objects" (Manovich 2001, 13-14). In fan works, different media forms interact with each other and determine the process of the original source transformation. Comparing the language of digital culture with the language of cinema and visual arts, Lev Manovich discusses the technique of transforming different media in the digital space. "Digital compositing in which different spaces are combined into a single seamless virtual space is a good example of the alternative aesthetics of continuity [...] compositing aims to blend them into a seamless whole, a single gestalt.” (Manovich 2001, 144.) Therefore, the creation of fanfiction is associated with two opposing mechanisms: 1) the use of basic, recognizable elements of one or several primary sources (it does not matter if they are literary or any other art-form); 2) the inclusion of specific changeable elements in the original text.

This form of media transformation is similar to the process of "digital compositing," when "some elements are created specifically for the project; others are selected from databases of stock material" (Manovich 2001, 136).

Another feature of fanfiction as a type of new media is the form of authorship. Amateur tags and fanfic genres developed by global community at the same time constitute its universal terminology and play the role of the "menus of software packages" (Manovich 2002, 3). The interface of sites containing fanfiction suggests that the authors value communication with each other, although the "author and the user are often two total strangers" (Manovich 2002, 2): fans can use other people's work along with conventional original sources. The question about the intermediality of fanfiction is discussed by Karin Wenz, who is trying to find a relationship between transmediality and intermediality. "If we understand intermediality [...] in the sense that several media lit at the basis of the production of the fan's narrative [...] fanfiction is intermedial." (Wenz 2010, 123.) Thus, fan literature acts as an intermedial environment distinguished by the fact that because of the transformation of the discrete features of different forms of art it develops new ways of interaction between the perceiving reader/spectator and the original source in the digital space. However, the question of how this converged environment transforms the original source (which is intermedial itself) remains open. The goals of fanfiction research are related to Müller's assertion that the research of the intermediality of new media can be focused on "how traditional audiovisual media 
and/or analogic sounds and images have left their traces in these digital worlds, what modalities could be reconstructed" (Müller 2010, 33).

The article's hypothesis is that due to the existence of two versions of Lolita - Russian and English -, fan texts in both language corpora differ in choice of linguistic means, but have similar narrative structures. Thereby, our research draws on the assumption that a fic writer models the original source and embodies this model in his or her creation. It allows us to describe the mechanisms of borrowing and interpretation of semantic elements of the original source in the transnational corpora of fan texts.

\section{Strategy of Interpretation of Nabokov's Lolita in Russian and English Fandoms}

\section{a) Comparison of Linguistic Features}

Vladimir Nabokov is a popular writer in the amateur authors' community. His heritage holds a special place on Russian- and English-speaking fic writers' websites: Lolita is the only novel by Nabokov presented in most of the fan texts. Due to the lack of a unified methodology for fan audience research (Barnes 2015, 74), the portrait of an ordinary fan author cannot be described in detail. We adhere to a general portrait of a fan writer based on the whole global fandom. The research devoted to fan practices convinces us that most fanfiction writers are young people (Black 2007; Thorne 2010) and "predominantly female" (Barnes 2015, 75).

In the case of the Lolita fandom, we can describe the cultural preferences of the community. On the one hand, fans perceive the narration about Lolita as a mass formula (Cawelty 2014, 35-36), given by various media adaptations, as a story about forbidden love of an adult man for a young girl. On the other hand, fic writers perceive Nabokov's novel as a text by a modern classic which is difficult to understand. The verbal technique as well as the characters of the novel are integral components of the text recognizability in amateur authors' reception. Fic writers' narrative strategies differ in the choice of style as a "sum of linguistic features associated with text" (Leech 2013, 54). By copying linguistic patterns of Lolita, fic writers act as amateur researchers: they try to "suggest distinctive 'mind-styles' in authors and characters" (Fowler 2003, IX).

In Lolita fandom, two different language strategies correspond to two different archives of fan texts (Russian- and English-speaking) and two different artistic forms (lyric or prose). 
One of the features of the English-speaking Lolita fandom is the formal predominance of prose texts over lyrical ones: poems are one-fifth of the fan corpora. The prosaic form of amateur texts chosen by fic writers correlate with the complex genre structure of the original source. In Nabokov's Lolita a detective story, pseudoresearch ("As a case history, Lolita will become. No doubt, a classic in psychiatric circles" [Nabokov 2011, 3]), diary and commentary on the cycle of poems (Humbert's parodies of the English poetry and his lyrical verdict on Quilty) are combined.

Fic writers often divide this genre combination and embody one of the dominant verbal techniques in their own texts. For example, fic writers copy diary features: they use first-person pronouns, reach out to fictional readers, and include words such as prose, style, note, and write to create a character's thoughts about the writing process: "and when this entry is completed in its fancy prose style I shall also endeavour that it is burned and destroyed" (A confession to trounce all others by Eureka234). Unlike the lyrical composition, the prosaic narration reflects Humbert's analytical mindset in amateur authors' reception. English-speaking fic writers note the duality of his narrative style, where his confession combines the pragmatic theory and witty literary references and allusions. In English fanfics, allusions are focused on the similarity between events and plots of the European classical literature and the events presented by Humbert. For example, the reference to Rostand's comedy Cyrano de Bergerac in the fanfic Colorado by xGraybackx: "Cyranose knew well that his Roxane had much faith in Christian, it - he was good and gracious." In fanfics the verbal game with metaphors and allusions is shown as mechanical and imitative.

The sangfroid of enamoured Humbert, who glorifies Lolita, allows fic writers to metaphorically compare the nymphet hunt and the narration about Lolita to a logical game. In the fanfic Fruhling In Paris by Lady_MidnightII, Humbert's double (similar to the character of Nabokov's other novel The Defence [The Luzhin Defence]) detects the game decorations in the world around him: "the tiles are black and white marble, like a great chessboard."

Humbert's capability to compare himself to other literary characters is determined in amateur texts by the implicit but conflict-forming character's claim to be an author of the entire text, who is free to use "semantic deviations" like a poetic metaphor (Leech 2014, 59). Despite the fact that Humbert's hidden motivation is not always recognized by the English-speaking fic writers, the interpretation of the event structure of Lolita can in general be described as Humbert's mind game. For fic writers, the character's mind game consists of his sophisticated verbal technique.

Unlike English texts, Russian fanfics are predominantly poetic and lyrical. Lyrical texts generally imply the presence of a lyrical hero as an "objectified author" (Bakhtin 
1999, 66), who corresponds to Humbert's narrative strategy. Contrariwise, a genre of the song used for the poetic paraphrase of the novel's plot introduces another voice into the monologic narration - the voice of Lolita, who is sensitive to melody and rhythm in the original novel. It is reflected in the rhythmical narration of the original novel: "sometimes [...] I could hear Lo's bare feet practicing dance techniques in the living room downstairs [...] and-one, and-two, and-one, and-two" (Nabokov 2011, 206). In poetic fanfics Russian-speaking fic writers use not only metrical forms (especially iambus), but include motifs of the rhythm or dance: "you know that I will run away, but you do not believe... / Someday I will dance on your grave" (I am no longer a child... [Ja ved' uzhe ne ditya...] by S.A.SH.A.) (our translation).

Russian-speaking fic writers do not single out analyticity as a stable component of the original novel, but rather an artistic ornateness and stylistic paradoxicality of Humbert's speech - inner duality of his voice, which is explained by his "madness." In Russian fanfiction, Humbert turns out to be a poet, and Lolita is not a real lover, but a muse of the inspired writer: "I don't remember for how long I have been looking at you, reading poems by heart about my love” (My Lo [Moja Lo] by Dancing with myself). Russian-speaking fan authors emphasize that the character does not act like a sharp hunter, but like a lunatic. Fic writers trust the unreliable narrator who calls himself a "maniac" in a commentary about his own poem.

Therefore, in the multilingual community the peculiarities of the interpretation of the novel can be explained by the perception of the linguistic features of two different variants of Nabokov's work. Russian- and English-speaking fic writers dealt with different sources. In The Postscript to the Russian Edition, Nabokov (1982b, 191) notes "the poetry of thought," which he was able to represent in the English version and which is not reflected in the auto-translation. In Englishspeaking fanfics, the combination of "natural" and "unnatural passions" is reflected in the repeated plot about admiring Lolita and simultaneously searching for signs indicating her demonic essence. Copying Humbert's narrative style, fic writers select common and literary words simultaneously: "was it once a sin to lay eyes upon the sacred Aztec gold? Surely, most assuredly, it was punishable by death" (Like Fire, Hellfire by fishstick) (our italics).

At the same time, "everything tenderly human, but also everything coarse and crude, juicy and bawdy" was conveyed in the Russian text (Nabokov 1982b, 191). Obviously, the "gestures, grimaces, landscapes, the torpor of trees, the odor, and rain” in the Russian version of Lolita were inspired by Russian classical poetry among other things. Thus, in the Russian-speaking fanfiction, similarly to the autotranslation (but not in the English original), Humbert acts as a reader of Pushkin's 
Eugene Onegin: "she is fragile and refined, like a forest fallow deer" (La folie by Emine_) - the portrayal of Lolita repeats that of Tatyana in Pushkin's novel.

\section{b) Comparison of Narrative Structure}

The texts of the international Lolita fandom are heterogeneous in terms of their aesthetic complexity. The main difference between the Russian- and Englishspeaking corpora is a selection of linguistic features. Multilingual Lolita fandoms use similar narrative patterns and have no nationally or culturally determined characteristics, besides the differences in style and pretext.

Firstly, the homogeneity of narrative variations of Lolita can be explained by the specifics of the two original sources, the author of which is bilingual and focuses both on the European and Russian readers. The novel Lolita turns out to be a space in which not only different national artistic traditions, but also different readers the carriers of these traditions - come together ("as a reader, I [...] can easily fill a huge sympathetic auditorium with my doubles”) (Nabokov 1982b, 197).

Secondly, uniformity of the narrative interpretations of Lolita in the Internet community is influenced by the image of Lolita, which is widespread in popular culture: film adaptations, musical variations of the heroine's image (in both the Russian- and English-speaking fan communities the work of the American singer Lana Del Rey is mentioned), advertising incarnations (for example, the advertisement for the perfume Lolita Lempicka, where the image of a butterfly girl is commercialized [Bertram and Leving 2013, 18]). Images and scenes that are repeated in visual adaptations and absent in the original source influence Russian-speaking and English-speaking fandoms. For example, Humbert watches Lolita sitting in a chair (Vanilla Chick by LivingSculptureofPemberley; One Way or Another by come along); Lolita chewing gum as an integral attribute of her image that is described in the novel only once (Lolita by Gone With the Wind, Colorado by xGraybackx).

The analysis of the fandom allows us to note that transformation of different forms of media into fanfiction is explicit precisely at the level of the narrative organization of the text. Writing the fanfics on Lolita involves not only reading a book or watching a movie, but also a reading-writing game based on other adaptations. The numerous media variants of Lolita impact the methods of fan writing: fic writers overlook the events of the novel itself; they create isolated excerpts, lost episodes. In most of the fanfics presented as Humbert's memories of Lolita, fic writers do not change the narrative structure of the original source, but model a possible scene that was missed in the novel. 
The distinctive feature of the lost episodes is their emphasized static nature and, obviously, orientation towards the language of visual arts (music video) and advertising. This process repeats the technology of "sampling" (Manovich 2001, 27): sustainable images of Lolita are "discrete" - they can be repeated in other texts. Within the boundaries of this intermedial game, Lolita is converted through audiovisual media. Firstly, it is carried out by the combination of text, hypertext and audio recordings, as, for example, in the fanfic You Miss the Point (by looneyngilo2), where the reader is invited to download and listen to the artistic reading of the fan text. Secondly, fic writers try to create the rhythm of their text through the division of the text into stanzas/paragraphs. For example, the author of the fanfic Lolipop Parks And A Girl Named Candy (by Lady_MidnightII) is trying to convey a counterpoint combining the music of The Killers and the performer Lana Del Ray in the lyrics about Lolita. Fic writers borrow gestures, mimic characters from the movies and use montage techniques: in the fanfic Your Lolita is no more (Tvojej Loliti bol'she net) by monsters_inside the image of an adult Lolita is combined with the image of a child Lolita who represents herself as a film actress - who is literally Lolita from the screen versions of the novel. Even if fic writers do not directly point to a song or film as a canon, and the only source present is the novel, the intermedial game continues. We suggest that fic writers fix intermediality as one of the stable features of Nabokov's novel itself. In general, such understanding of Lolita is close to the author's perception of the reader as a spectator. "We have no physical organ (as we have the eye in regard to a painting) that takes in the whole picture and then can enjoy its details. But at a second, or third, or fourth reading we do, in a sense, behave towards a book as we do towards painting." (Nabokov 1982a, 3.) Therefore, the process of readers' "digital composing” implies rereading.

Narrative structure in fragmentary texts is incomplete: it is only clear that Lolita is an object of Humbert's desire. On the one hand, in the original source Lolita in her trying to mimic the actresses from posters, is "the ideal consumer of advertising" (Nabokov 2011, 167). On the other hand, Humbert's narration begins to parody advertisements: "and I doubt not that you and I would make a pretty ad for the Traveling Agency when portrayed looking-you” (Nabokov 2011, 101). The fragmentation of the story about Lolita into many scenes set by the narrator in the first part of his confession ("She was Lola in slacks. She was Dolly at school" [Nabokov 2011, 7]), as well as the search for Lolita's doubles, is motivated by Humbert's desire to immortalize his beloved, to stop the time. The glorifying of the demonic Lolita, whom Humbert in his Confession compared to the immortal literary and artistic nymphets, takes the form of an advertisement or a piece of poor 
quality literature. Brian Boyd connects this narrative anomaly with the character's perverted imagination: "his attractive urge to transcend the self decays at once into nothing more than its own parody, into the mere promotion of self" (Boyd 1991, 228). Fic writers, creating their own work in form of a fragment, continue the narrative strategy of Humbert - unreliable narrator. In these fragments, the conflict between Humbert and the reality, in which Lolita is a child, does not end, but only intensifies: "And these tender memories / Fade into the black screen / Leaving only heartbeats / Eternally reminding me that / You will always be / My vision quest" (Looking for Lolita by HappyHippy).

Fanfiction fragments demonstrate the limited possibilities of narrative modelling as they resemble lyrical genres, whereas in the rest of the texts of the international fandom two dominant narrative principles are prevalent.

The first narrative structure is created by the transition from a four-actantial model (McFate 2 /Humbert - Lolita/reader) to a two-actantial model (Humbert - Lolita). It allows fic writers to transpose any popular work into the plot framework of the novel Lolita. Most of these texts (listed in the crossover category and involving popular fandoms like Marvel comic books, Harry Potter universe or the Star Wars trilogy) focus on the forbidden relations of the main characters. Although these fanfics clearly reference Lolita, it is unclear what influenced them more - Nabokov's novel or modern TV series and comics.

Another implementation of this narrative model is the transformation of Lolita into a detective story or a thriller, which presumes the presence of an "ignorant" character as a subject. The event in this fanfiction is the disclosure of secrets. In the Russian fanfic One way or another (by comes along) the plot of Lolita is integrated into the story of the rivalry between detective Sherlock Holmes and Professor Moriarty (Humbert). Humbert-Moriarty is a criminal and insane genius who destroys Lolita's life. The ignorant heroine is the narrator in the fanfic. A similar plot structure is used in the English fanfic Any Other Name (by PeekabooFang), the crossover of Lolita and the Batman comic books. The husband of Lolita plays the role of an ignorant character, who loses his mind after his wife's death, becomes a villain (Joker, the main opponent of Batman), and kills Humbert. Despite the fact that this interpretation of Lolita is close to its "highly moral" meaning (Nabokov and Wilson 2001, 331), fic writers do not notice the imaginary nature of the whole world invented by Humbert. Any attempt to evaluate the actions of Humbert from the point of view of possible carriers of common sense ends in failure: it is symptomatic that the same characters of fanfiction turn into madmen in the end.

2 Humbert gives the alias to his own fate. 
("Because he could not disappear. Because he settled in her." [Any Other Name by PeekabooFang])

In fanfics, transposition of quotations from the original source arises due to the perception of Nabokov's self-quotations ("self-referential elements" [Rampton 1984, IX]) in the novel itself. Fic writers use quotes to amplify the connection of their texts with the original novel. However, the citation is inherent in the fanfics with an incomplete narrative structure and an imitative style. In the original source, the auto-citations mark the presence of another creative consciousness unnoticed by Humbert. This creative consciousness permits the elements of hypertext in the character's confession (for example, reference to the finale of the novel The Luzhin Defense: "But there was no Charlotte in the living room" [Nabokov 2011, 109]).

Therefore, the use of the first narrative scheme leads to the exit from the field of fiction and to the distortion of the original source, in which one of the main actors (sender) is the creator McFate (Nabokov 2011, 120), existing outside of Humbert's world.

The second narrative structure organizes a much smaller number of texts in the international fandom. It changes the composition of narrators and subjects of speech in general. Nabokov-writer is displayed by fic writers as a character of a special type (character-writer). For example, in the poem Write Me Already, Write (Pishi zhe menya, pishi by Matvey.snezhhy.) the plot is built around a dialogue between the characters of the novel and the character-writer. In this poem, the object of the conversation of three voices is the reality of unfolding events: "Lolita is dead. But her voice is ringing;" "He asks you to understand [...] / That his love is real and it really exists." In the English-speaking fanfic A confession to trounce all others (by Eureka234), the name of Humbert's beloved, which is generally mentioned often by other fic writers, is verbalized only once. In his own diary, the character focuses not so much on Lolita but on his attempted murder of Charlotte Haze. Humbert convinces readers of his involvement in the murder of his wife, denying the role of McFate (the other possible character-writer): "Lenient members of the jury, let it be duly noted that I murdered her first." ( A confession to trounce all others by Eureka234.)

Thus, the motivation of the other actants introduced by fic writers is connected to the characters' exit from the textual reality of Nabokov's novel or the creation of their own text, in which the time would be subordinated to the will of the character-writer. Both in Russian and English fanfiction, the interaction and even the rivalry between two creative forces are brought to the fore as the key event of the original novel. 


\section{Conclusion}

Fanfiction as a new medium constantly interacts with other forms of media. The interface of fan communities (forum, archive, and gallery) and the reader game itself involves the constant transformation of other works and the modelling of original interpretation in the digital environment. Converting the source, fic writers investigate its kernel: "we may imagine a community formed around some creative work: this community would agree on what constitutes the kernel of this work" (Manovich 2002, 10). Therefore, the original source itself, presented in fic writers' interpretative works, leaves its original trace in digital environment: the more converted various media are in the original source, the more actively it is transferred to the intermedial fanfiction. In the novel Lolita, various forms of conversion of other aesthetic realities are reinterpreted, and the protagonist himself is ultimately subservient to others' artistic concept. Therefore, in the fan milieu, the Lolita narrative strategy acts as a universal model for any kind of transformations of an artistic text, including the transformation of the language of new media.

Unlike other fandoms based on classical literature, where unrealized but possible narrative lines are highlighted, amateur adaptations of the novel Lolita demonstrate fic writers' strict adherence to the style and structure of the original source. By copying the images of the original source, seeking to preserve its style, fic writers reproduce the key motif of the novel, but do not always recognize its role in the forming of the events in Nabokov's text. Thus, the complex system of actants in the original source continues to function in its various media adaptations. In the case of blind copying or parodying, the adapter continues the narration begun by Humbert, who is also blind to the extra-textual reality manifested even in his own confession. The novel, which tells about an erroneous interpretation, is open to any misinterpretations and to any massmedia adaptations. This narrative feature of Lolita is interpreted in the ironic preface of the novel, where all possible variants of the distortion of Lolita are predicted.

The narrative analysis of the texts in Lolita fandom allows us to speak about fanfiction not only as a reading practice, but also as a practice of amateur intermedial research. The purpose of rewriting the original is not only the experiment with the text but also its research. As a result of the rewriting, fic writers either recognize the meta-literary nature of the text or perceive Humbert's defensive speech as reliable and ignore Nabokov's game with the "duplicity of inner speech" (Genette 1983, 178) that relates both to the action and the act of writing. Fan interpretation of the modern classic is based only on what lies within the text or its various media adaptations. "The interpretation demanded by a specific text, in its plurality, is 
in no way liberal: [...] it is a question, against all in-difference, of asserting the very existence of plurality, which is not that of the true, the probable, or even the possible." (Barthes 2002, 6.) Emergence and spreading of such form of transmedial translation as fanfiction, where the reader acts as a co-author, makes the narrative combination of Nabokov's novel Lolita even more obvious. It is structured in such a way that even an amateur text re-created as a result of misinterpretation continues the author's strategy delineated in the original source. It is obvious that along with the actant-creator, or McFate, implicit in Nabokov's novel, there is another potential actant - the receiver-reader, an obligatory participant in the aesthetic game.

\section{References}

Aarva, Pauliina, and Marja Pakarinen Tampere. 2006. Studying the Striving and Opposing Forces in Newspaper Journalism: The Actantial Model of Health Promotion. Health Promotion International vol. 21, no. 2: 160-168.

Archive of Our Own (The Organization for Transformative Works). https:// archiveofourown.org. Last accessed 11. 06. 2019.

Bakhtin, Mikhail. 1999 [1993]. Toward a Philosophy of the Act. Austin: University of Texas Press.

Barnes, Jennifer L. 2015. Fanfiction as Imaginary Play: What Fan-Written Stories Can Tell us about the Cognitive Science of Fiction. Poetics vol. 48: 69-82.

Barthes, Roland. 1977. Image Music Text. London: Fontana Press.

Barthes, Roland. 1989. The Rustle of Language. Berkeley and Los Angeles: University of California Press.

Barthes, Roland. 2002 [1990]. S/Z. Oxford: Blackwell Publishing.

Beddows, Emma. 2012. Consuming Transmedia: How Audiences Engage with Narrative across Multiple Story Modes. PhD thesis, Swinburne University of Technology, Australia. http://researchbank.swinburne.edu.au/vital/access. Last accessed 11. 06. 2019.

Bertram, John and Yuri Leving. 2013. Lolita - The Story of a Cover Girl: Vladimir Nabokov's Novel in Art and Design. New York: Simon and Schuster.

Black, Rebecca W. 2006. Language, Culture, and Identity in Online Fanfiction. E-Learning and Digital Media vol. 3, no. 2: 170-184.

Black, Rebecca W. 2007. Fanfiction Writing and the Construction of Space. E-Learning and Digital Media vol. 4, no. 4: 384-397.

Boyd, Brian. 1991. Vladimir Nabokov: The American Years. Princeton, New Jersey: Princeton University Press. 
Brooker, Will. 2017. A Sort of Homecoming: Fan Viewing and Symbolic Pilgrimage. In Fandom, Second Edition: Identities and Communities in a Mediated World, eds. Jonathan Gray, Cornel Sandvoss and C. Lee Harrington, 157-173. New York: New York University Press.

Burchill, Julie. 1986. Damaged Gods: Cults and Heroes Reappraised. London: Century.

Cawelti, John G. 2014 [1977]. Adventure, Mystery, and Romance: Formula Stories as Art and Popular Culture. Chicago and London: University of Chicago Press.

DiMaggio, Paul. 1977. Market Structure, the Creative Process, and Popular Culture: Toward an Organizational Reinterpretation of Mass-Culture Theory. The Journal of Popular Culture vol. 11, no. 2: 436-452.

FanFiction. https://www.fanfiction.net. Last accessed 12. 10. 2018.

Fernández-Morales, Marta and María Isabel Menéndez-Menéndez. 2013. Gender Violence and Gendered Agency within the Actantial Paradigm of Person of Interest. Concordia Discors vs Discordia Concors: Researches into Comparative Literature, Contrastive Linguistics, Translation and Cross-Cultural Strategies vol. 5: 131-161.

Fiske, John. 2001. The Cultural Economy of Fandom. In The Adoring Audience: Fan Culture and Popular Media, ed. Lisa A. Lewis, 30-49. London and New York: Routledge.

Fowler, Roger. 2003. Linguistics and the Novel. London and New York: Routledge. Genette, Gerard. 1983 [1980]. Narrative Discourse: An Essay in Method. Ithaca, New York: Cornell University Press.

Gray, Jonathan, Cornel Sandvoss and C. Lee Harrington, eds. 2017. Fandom, Second Edition: Identities and Communities in a Mediated World. New York: New York University Press.

Greimas, Algirdas Julien. 1986. Sémantique structurale: Recherche de méthode [Structural Semantics: An Attempt at a Method]. Paris: Presses Universitaires de France.

Guerrero-Pico, Mar. 2016. Dimensional Expansions and Shiftings: Fan Fiction and Transmedia Storytelling [in] the Fringeverse. Series-International Journal of TV Serial Narratives vol. 2, no. 2: 73-85.

Hills, Matt. 2012. Torchwood's Trans-Transmedia: Media Tie-Ins and Brand 'Fanagement.' Participations vol. 9, no. 2: 409-428.

Jancovich, Mark. 2002. Cult Fictions: Cult Movies, Subcultural Capital and the Production of Cultural Distinctions. Cultural Studies vol. 16, no. 2: 306-322. 
Jenkins, Henry. 1992. Textual Poachers: Television Fans and Participatory Culture. New York and London: Routledge.

Jenkins, Henry. 2006. Convergence Culture: Where Old and New Media Collide. New York: New York University Press.

Jenkins, Henry. 2007. Transmedia Storytelling 101. http://henryjenkins.org/ blog/2007/03/transmedia_storytelling_101.html. Last accessed 12. 01. 2018.

Jewett, Robert and John S. Lawrence. 1977. The American Monomyth. Garden City, New York: Anchor Press.

Johnson, Derek. 2007. Fan-tagonism: Factions, Institutions, and Constitutive Hegemonies of Fandom. In Fandom: Identities and Communities in Mediated World, eds. Jonathan Gray, Cornel Sandvoss and C. Lee Harrington, 285-300. New York and London: New York University Press.

Kniga Fanfikov [Book of Fanfics]. https://ficbook.net. Last accessed 11. 06. 2019. Leech, Geoffrey. 2013 [2008]. Language in Literature: Style and Foregrounding. London and New York: Routledge.

Magnifico, Alecia Marie, Jen Scott Curwood and Jayne C. Lammers. 2015. Words on the Screen: Broadening Analyses of Interactions among Fanfiction Writers and Reviewers. Literacy vol. 49, no. 3: 158-166.

Manovich, Lev. 2001. The Language of New Media, MA: MIT press.

Manovich, Lev. 2002. Models of Authorship in New Media. http://manovich.net/ content/04-projects/035-models-of-authorship-in-new-media/32_article_2002. pdf. Last accessed 11. 06. 2019.

Marlow, Christopher. 2009. The Folding Text: Doctor Who, Adaptation and Fan Fiction. In Adaptation in Contemporary Culture: Textual Infidelities, ed. Rachel Carroll, 46-58. London: Continuum, 2009.

McGee, Jennifer. 2005. "In the End, It' s All Made Up:" The Ethics of Fanfiction and Real Person Fiction. In Communication Ethics, Media and Popular Culture, eds. Phyllis M. Japp, Mark Meister and Debra K. Japp, 161-180. New York, Washington, etc.: Peter Lang.

Müller, Jürgen E. 2010. Intermediality and Media Historiography in the Digital Era. Acta Universitatis Sapientiae, Film and Media Studies vol. 2: 15-38.

Murray H., Janet. 2017 [1997]. Hamlet on the Holodeck: The Future of Narrative in Cyberspace. Cambridge, Massachusetts: MIT Press.

Nabokov, Vladimir and Edmund Wilson. 2001. Dear Bunny, Dear Volodya: The Nabokov-Wilson Letters, 1940-1971. Berkeley, Los Angeles, London: University of California Press. 
Nabokov, Vladimir. 1982a. Good Readers and Good Writers. In Lectures On Literature, 1-8. New York: A Harvest Book.

Nabokov, Vladimir. 1982b. Postscript to the Russian Edition of Lolita. In Nabokov's Fifth Arc: Nabokov and Others on His Life's Work, eds. J. E. Rivers and Charles Nicol, 188-197. Austin: University of Texas Press.

Nabokov, Vladimir. 2011 [1995]. Lolita. London: Penguin Books.

Propp, Vladimir. 2003 [1986]. Morphology of the Folktale. Austin: University of Texas Press.

Rampton, David. 1984. Vladimir Nabokov: A Critical Study of the Novels. Cambridge: Cambridge University Press.

Russo, Julie Levin. 2009. User-Penetrated Content: Fan Video in the Age of Convergence. Cinema Journal vol. 48, no. 4: 125-130.

Sandvoss, Cornel. 2007. The Death of the Reader? Literary Theory and the Study of Texts in Popular Culture. In Fandom: Identities and Communities in Mediated World, eds. Jonathan Gray, Cornel Sandvoss and C. Lee Harrington, 19-34. New York and London: New York University Press.

Thomas, Bronwen. 2011. What Is Fanfiction and Why Are People Saying Such Nice Things about It? Storyworlds: A Journal of Narrative Studies vol. 3: 1-24.

Thorne, Steven L. 2010. The "Intercultural Turn" and Language Learning in the Crucible of New Media. Telecollaboration vol. 2: 139-164.

Tulloch, John. 2007. Fans of Chekhov: Re-Approaching "High Culture". In Fandom: Identities and Communities in Mediated World, eds. Jonathan Gray, Cornel Sandvoss and C. Lee Harrington, 110-124. New York and London: New York University Press.

Van Steenhuyse, Veerle. 2014. Wordplay, Mindplay: Fan Fiction and Postclassical Narratology. Transformative Works and Cultures no. 17. http://dx.doi.org/10. 3983/twc.2014.0572. Last accessed at 11. 06. 2019.

Viires, Piret. 2005. Literature in Cyberspace. Folklore: Electronic Journal of Folklore no. 29: 153-174.

Wenz, Karin. 2010. Storytelling Goes On After the Credits. In Reading Moving Letters: Digital Literature in Research and Teaching. A Handbook, eds. Roberto Simanowski, Jörgen Schäfer and Peter Gendolla, 109-128. Bielefeld: transcript Verlag.

Woloch, Alex. 2003. The One vs. the Many: Minor Characters and the Space of the Protagonist in the Novel. Princeton and Oxford: Princeton University Press. 